The Israeli Journal of Aquaculture - Bamidgeh, IJA_69.2017.1402, 8 pages

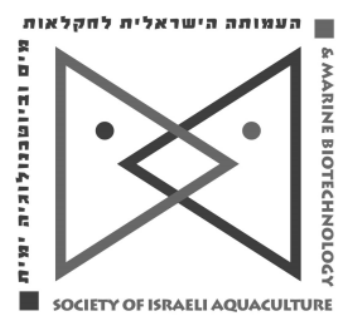

The IJA appears exclusively as a peer-reviewed on-line open-access journal at http://www.siamb.org.il. To read papers free of charge, please register online at registration form.

Sale of $I J A$ papers is strictly forbidden.

\title{
Effects of Dietary Supplemental of AAMC, an Anionic Alkali Mineral Complex, for Pacific White Shrimp (Litopenaeus vannamei)
}

\author{
Hien Thi Dieu Bui ${ }^{1}$, Sanaz Khosravi', Chorong Lee ${ }^{1}$, Min-Gi Kim ${ }^{1}$, \\ Se-Jin Lim², Chang-Hoon Shin ${ }^{3}$, Byung-Woo Yoo ${ }^{3}$, Soo-Il Choi ${ }^{4}$, \\ Kyeong-Jun Lee ${ }^{1 *}$
}
${ }^{1}$ Department of Marine Life Sciences, Jeju National University, Jeju 63243, South Korea
${ }^{2}$ Neo Environmental Business Co. Dangjin-si, Chungcheongnam-do, South Korea

\author{
${ }^{3}$ Cargill Agri Purina Inc, Seongnam, Gyeonggi, South Korea \\ ${ }^{4}$ Barodon - S.F. Crop, Ansung, Gyeonggi, South Korea
}

\begin{abstract}
Keywords: Litopenaeus vannamei; aninonic alkali mineral complex; growth performance; innate immunity; disease resistance
\end{abstract}

\begin{abstract}
A 6-week feeding trial was conducted to evaluate the effect of dietary supplementation of Anionic Alkali Mineral Complex (AAMC) on growth performance, feed utilization, innate immunity, and disease resistance of $L$. vannamei. Graded levels of AAMC solution were included in a basal diet; $0 \%$ (Control), $0.05 \%, 0.1 \%, 0.2 \%$ and $0.4 \%$. Shrimp fed diets supplemented with $0.2 \%$ and $0.4 \%$ AAMC had the highest growth performance, and compared to the control treatment, final body weight and specific growth rates were significantly higher $(P<0.05)$. Feed utilization also improved significantly with AAMC supplementation. Non-specific immune responses of shrimp were significantly affected by dietary supplementation of AAMC; total hemocyte count of shrimp fed $0.1 \%$ and $0.2 \%$ diets was significantly higher the control diet shrimp group. Phenoloxidase and lysozyme activity was significantly higher in shrimp fed $0.2 \%$ diet compared to the control diet group. Glutathione peroxidase activity was significantly enhanced with dietary supplementation of $0.1 \%-0.2 \%$ AAMC. In a challenge test with Vibrio harveyi, shrimp fed $0.2 \%$ AAMC disease resistance was significantly higher than in shrimp fed the control diet. Overall, the results indicate that dietary supplement of AAMC improved growth, diet utilization, innate immunity, and disease resistance of Pacific white shrimp and approximately $0.2 \%$ in diets appeared to be the optimum supplemental level.
\end{abstract}

\footnotetext{
* Corresponding author. Tel: +82-64-754-3423, Fax: +82-64-756-3493,
} email: kjlee@jejunu.ac.kr 


\section{Introduction}

Diseases caused by infectious microorganisms, particularly Vibrio spp., have been major constraints in the shrimp industry (Flegel et al., 2008; Williams et al., 2017). This has led to the abuse and overuse of antibiotics in the industry ( $\mathrm{Ng}$ et al., 2015). The uncontrolled use of antibiotics has given rise to other problems, such as spread of drug resistant pathogens, and negative impacts on host species and the environment (Marshall and Levy, 2011). Long-term use of antibiotics reduced their effectiveness due to emergence of resistant bacterial strains, including $V$. harveyi, in shrimp (Rebouças et al., 2011) and has been reported to negatively affect shrimp growth and health (Sheikh et al., 2017). Consequently, it is important to find alternative antibiotics or alternatively stimulate natural host defense mechanisms. Dietary immunostimulants are used to boost the immune system and improve resistance to infectious diseases in shrimp.

Several immunostimulants including synthetic chemicals and natural biological substances have widely been used worldwide (Chen et al., 2016). AAMC, an anionic alkali mineral complex, has been identified as a potential immunostimulant in terrestrial animals, such as pigs and horses (Yoo et al., 2001; Koo et al., 2006). The main compositions of AAMC are silicon, potassium, sodium, and boron ions in an alkaline solution ( $\mathrm{pH}$ 13.5). AAMC was patented as a nonspecific immunostimulator in South Korea, USA, and South Africa (Choi et al., 2005). Its immunomodulatory activity was observed through proliferation and activation of porcine immune cells, particularly $\mathrm{CD}^{+}$ $\mathrm{CD}^{+}$double-positive $\mathrm{T}$ lymphocytes in peripheral blood, and the secondary lymphoid organs (Yoo et al., 2001). It also has an adjuvant effect on hog cholera vaccine (Park et al., 2000). In fish, previous studies using dietary AAMC supplementation have shown improved innate immunity and thereby increased disease resistance of juvenile olive flounder (Shin et al., 2014a; Shin et al., 2014b).

To the best of our knowledge, no information exists regarding the use of AAMC as a dietary supplement for shrimp. We investigated the effect of supplementation of AAMC in diets for in Pacific white shrimp, L. vannamei, on growth performance, feed utilization, innate immunity, and subsequent disease resistance to $V$. harveyi.

\section{Materials and methods}

Experimental diets and design. A basal experimental diet was prepared and supplemented with $0.0 \%$ (Control), $0.05 \%, 0.1 \%, 0.2 \%$ and $0.4 \%$ AAMC. AAMC solution tested in this study was provided by Cargill Agri Purina, Inc. and Barodon-S.F. Corp., South Korea (Shin et al., 2014a; Shin et al., 2014b). All dry materials were thoroughly mixed with fish oil and double distilled water containing AAMC solution. The mixture was pelleted into $3.5 \mathrm{~mm}$ diameter pellets in a meat grinder (SMC-12; Kuposlice, Busan, Korea). The pellets were dried at $25^{\circ} \mathrm{C}$ for $24 \mathrm{~h}$, then crushed into desired particle sizes, and stored at $-20^{\circ} \mathrm{C}$ until use. See Table 1 for formulation and proximate composition of the experimental diets.

Table 1. Dietary formulation and proximate composition of the five experimental diets for $L$. vannamei (\% dry matter). AAMC stands for an anionic alkali mineral complex.

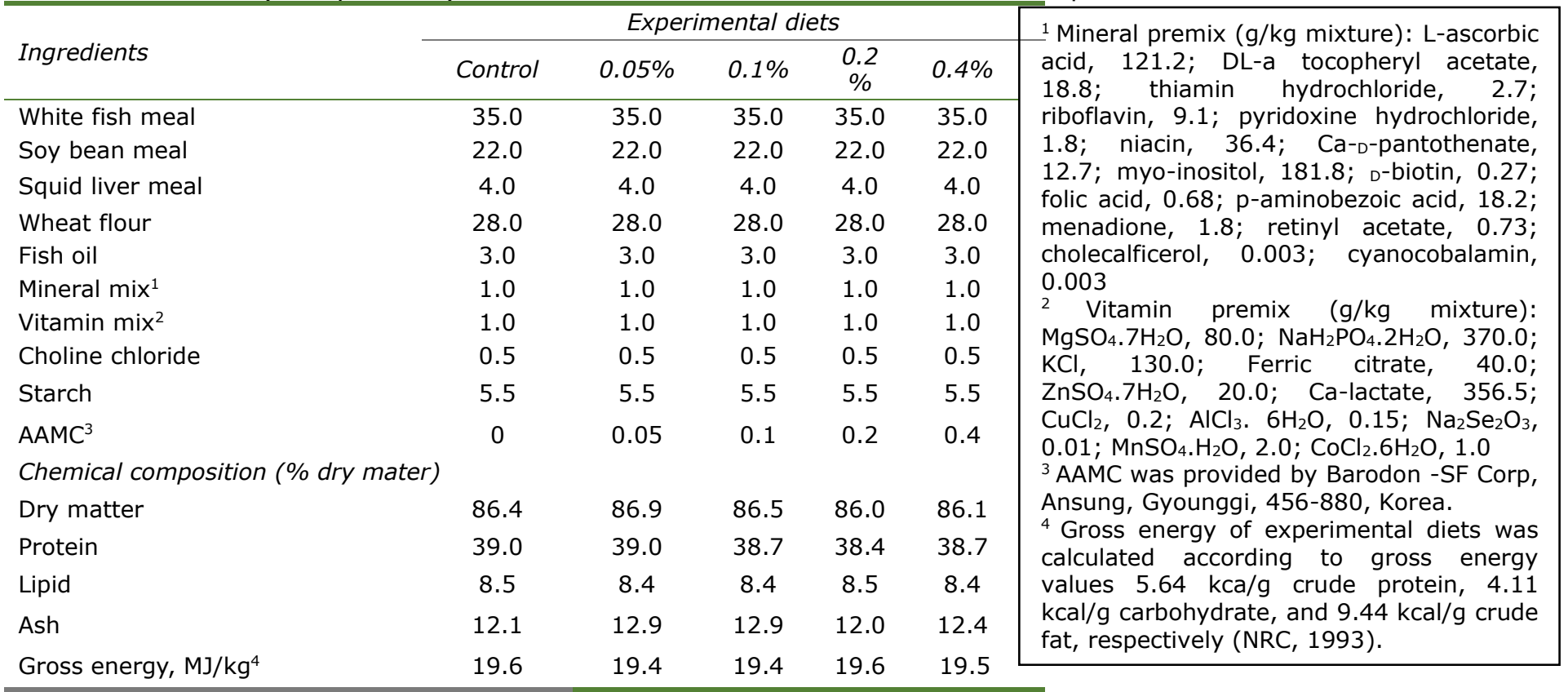


Shrimp and feeding trial. The 6 week feeding trial was conducted in an indoor shrimp culture facility at the Research Institute of Marine Science, Jeju National University (Jeju, South Korea). L. vannamei were provided from NeoEnBiz shrimp farm (Dangjin, South Korea). Shrimp were acclimated for 10 days during which they were fed a commercial diet (35\% crude protein) three times a day. At the end of the acclimation period, the shrimps with an initial weight of $3.98 \pm 0.01 \mathrm{~g}$ were randomly distributed into twenty acryl aquaria of $120 \mathrm{~L}$ capacity at a density of 30 shrimp per aerated aquarium filled with filtered seawater. Quadruplicate groups of shrimp were hand-fed with one of the test diets four times a day at 08:00, 12:00, 16:00 and 19:00 h. Daily feeding rate was gradually reduced from $10 \%$ to $8 \%$ of wet body weight during the feeding trial. Water was changed every three days and the aquaria cleaned with a sponge to prevent the growth of microflora. Fluorescent lighting for 12 hours maintained $12 \mathrm{~h}$ light/dark regime. The water temperature was $28 \pm 1^{\circ} \mathrm{C}, \mathrm{pH}$ fluctuated between 7.04-8.04, dissolved oxygen was above $6.0 \mathrm{mg} / \mathrm{L}$, and total ammonia nitrogen and nitrite were lower than 0.1 and $0.005 \mathrm{mg} / \mathrm{L}$, respectively. Shrimp growth was measured every 2 weeks. Feeding stopped $16 \mathrm{~h}$ before weighing or hemolymph sampling to minimize handling stress on shrimp.

Sample collection and analyses. At the end of the feeding trial, all shrimp in each tank were counted and bulk-weighed to assess growth and survival. Four shrimp per tank were randomly selected and kept at $-45^{\circ} \mathrm{C}$ for whole-body proximate composition analyses. Six shrimp per tank (24 shrimp per dietary treatment) were randomly taken and anesthetized with ice-cold water. The hemolymph samples $(200 \mu \mathrm{l})$ were individually collected from the ventral sinus of shrimp with a $1 \mathrm{ml}$ syringe (25-gauge needle) filled with an anticoagulant solution (Alsever's solution, Sigma). The hemolymph-anticoagulant mixture (diluted hemolymph) was placed in five sterile Eppendorf tubes containing equal volumes of pre-cooled anticoagulant to determine total hemocyte counts (THC) and respiratory burst activity. The remaining samples were centrifuged at $700 \times g$ for 10 min using a high-speed refrigerated microcentrifuge (Micro 17 TR; HanilBioMed Inc., Gwangju, South Korea) and stored at $-70^{\circ} \mathrm{C}$ for determination of total protein, phenoloxidase (PO), lysozyme, superoxide dismutase (SOD), and glutathione peroxidase (GPx) activity. Analysis of moisture and ash content of the diets and whole-body samples were performed using standard procedures (AOAC, 1995).

Monitoring of non-specific immune responses. A drop of the diluted hemolymph was placed in a hemocytometer to measure THC using an inverted phase-contrast microscope (Olympus, Model CH30RF200, Olympus Optical Co., LTD, Japan). Diluted hemolymph protein content was measured by a microprotein determination method (C-690; Sigma). Oxidative radical production by hemocytes during respiratory burst was measured with nitro-blue-tetrazolium (NBT) assay described by Dantzler et al. (2001). PO activity was measured spectrophotometrically by recording the formation of dopachrome produced from L-dihydroxyphenylalanine (L-DOPA, Sigma) following the procedure of HernandezLopez et al. (1996). Lysozyme activity was determined following a previously described method (Paglia and Valentine, 1967). SOD activity was measured by the percentage reaction inhibition rate of enzymes with WST-1 (water-soluble tetrazolium dye) substrate and xanthine oxidase using a SOD Assay Kit (Sigma, 19160) according to the manufacturer's instructions. Each endpoint assay was monitored by absorbance at 450 $\mathrm{nm}$ after $20 \mathrm{~min}$ of reaction time at $37^{\circ} \mathrm{C}$. Inhibition percentage was normalized by $\mathrm{mg}$ protein and presented as SOD activity units. GPX activity was assayed with a kit (Biovision, Inc., Milpitas, CA, USA).

Challenge test. At the end of the feeding trial, 10 shrimp from each tank ( 40 shrimp per treatment) were randomly selected and subjected to a bacterial challenge. $V$. harveyi was used as the pathogenic agent (provided by the Marine Microbiology Laboratory of Jeju National University). The shrimp were injected intramuscularly with $V$. harveyi suspension containing $1 \times 10^{6} \mathrm{CFU} / \mathrm{mL}$. The dose of bacterium had previously been determined in a preliminary test using shrimp of a similar size. After the injection, the shrimp were distributed into twenty $65 \mathrm{~L}$ plastic tanks, and mortality was monitored and recorded for 17 days. 
Statistical analysis. All dietary treatments were assigned in a completely randomized design. Data were subjected to one-way analysis of variance (ANOVA) in SPSS version 12.0 (SPSS Inc., Chicago, IL, USA). When ANOVA identified differences among groups, the mean differences were compared with Tukey's HSD multiple range tests. Statistical significance was determined at $P<0.05$ and data are presented as mean \pm SD. Percentage data were arcsine transformed before analysis.

\section{Results}

Growth performance and feed utilization of the shrimp were significantly affected by dietary supplementation of AAMC (Table 2).

Table 2. Growth performance and feed utilization of $L$. vannamei fed the five experimental diets for 6 weeks. The diets were added with graded levels of AAMC by $0,0.05,0.1,0.2$ and $0.4 \%$. AAMC stands for an anionic alkali mineral complex.

\begin{tabular}{|c|c|c|c|c|c|}
\hline & Control & $0.05 \%$ & $0.1 \%$ & $0.2 \%$ & $0.4 \%$ \\
\hline IBW $^{1}$ & $3.99 \pm 0.06$ & $3.96 \pm 0.04$ & $3.99 \pm 0.03$ & $3.99 \pm 0.04$ & $3.99 \pm 0.06$ \\
\hline $\mathrm{FBW}^{2}$ & $9.43 \pm 0.29^{b}$ & $10.3 \pm 0.14^{\mathrm{ab}}$ & $10.1 \pm 0.38^{\mathrm{ab}}$ & $10.7 \pm 0.75^{a}$ & $10.6 \pm 0.31^{a}$ \\
\hline$W^{3}$ & $136 \pm 7.6^{\mathrm{b}}$ & $159 \pm 2.1^{\mathrm{ab}}$ & $153 \pm 9.0^{\mathrm{ab}}$ & $168 \pm 20.7^{a}$ & $166 \pm 7.5^{a}$ \\
\hline $\mathrm{SGR}^{4}$ & $2.21 \pm 0.08^{b}$ & $2.44 \pm 0.02^{a}$ & $2.38 \pm 0.09^{a b}$ & $2.52 \pm 0.19^{a}$ & $2.51 \pm 0.07^{a}$ \\
\hline $\mathrm{FCR}^{5}$ & $2.11 \pm 0.15^{a}$ & $1.92 \pm 0.03^{\mathrm{ab}}$ & $1.96 \pm 0.04^{\mathrm{ab}}$ & $1.81 \pm 0.24^{\mathrm{b}}$ & $1.82 \pm 0.10^{\mathrm{b}}$ \\
\hline PER $^{6}$ & $1.22 \pm 0.09^{b}$ & $1.33 \pm 0.02^{a b}$ & $1.32 \pm 0.03^{a b}$ & $1.46 \pm 0.21^{a}$ & $1.42 \pm 0.08^{a}$ \\
\hline $\mathrm{FI}^{\prime}$ & $11.5 \pm 0.51$ & $12.1 \pm 0.05$ & $12.0 \pm 0.58$ & $12.0 \pm 0.65$ & $12.1 \pm 0.65$ \\
\hline Survival (\%) & $92.5 \pm 6.9$ & $94.2 \pm 4.2$ & $95.0 \pm 4.3$ & $94.2 \pm 4.2$ & $91.7 \pm 4.3$ \\
\hline
\end{tabular}

Values are mean of triplicate groups and presented as mean \pm S.D. Values with different superscripts in the same row are significantly different $(P<0.05)$. The lack of superscript letter indicates no significant differences among treatments.

${ }^{1}$ IBW: initial body weight $(\mathrm{g})$

${ }^{2}$ FBW: final body weight $(\mathrm{g})$

${ }^{3}$ Weight gain $(\%)=100 \times$ (final mean body weight - initial mean body weight)/initial mean body weight

${ }^{4}$ Specific growth ratio $\left(\%\right.$ day $\left.^{-1}\right)=[($ In final body weight - In initial body weight $) /$ days $] \times 100$

${ }^{5}$ Feed conversion ratio $=$ dry feed fed $(\mathrm{g}) /$ wet weight gain $(\mathrm{g})$

${ }^{6}$ Protein efficiency ratio $=$ wet weight gain $/$ total protein given

${ }^{7}$ Feed intake $=$ dry feed consumed $(\mathrm{g}) /$ shrimp

Growth rate and feed efficiency improved significantly in shrimp fed $0.2 \%$ and $0.4 \%$ diets compared to those fed the control diet. Dietary treatments with AAMC solution had no significant effect on feed intake (FI) and survival. Shrimp fed $0.1 \%$ and $0.2 \%$ diets showed significantly higher THC and GPx values than those fed the control diet (Table 3).

Table 3. Non-specific immune responses of $L$. vannamei fed the five experimental diets for 6 weeks. The diets were added with graded levels of AAMC by $0,0.05,0.1,0.2$ and $0.4 \%$. AAMC stands for an anionic alkali mineral complex.

\begin{tabular}{lccccc}
\hline & Control & $0.05 \%$ & $0.1 \%$ & $0.2 \%$ & $0.4 \%$ \\
\hline THC $^{1}$ & $259 \pm 37.8^{\mathrm{b}}$ & $299 \pm 47.4^{\mathrm{ab}}$ & $390 \pm 91.1^{\mathrm{a}}$ & $410 \pm 62.0^{\mathrm{a}}$ & $306 \pm 45.9^{\mathrm{ab}}$ \\
Total protein & $178 \pm 17.6$ & $189 \pm 13.9$ & $215 \pm 8.4$ & $208 \pm 29.2$ & $197 \pm 32.7$ \\
NBT $^{3}$ & $2.55 \pm 0.10$ & $2.95 \pm 0.43$ & $3.00 \pm 0.28$ & $2.85 \pm 0.32$ & $2.79 \pm 0.24$ \\
PO $^{4}$ & $0.15 \pm 0.01^{\mathrm{b}}$ & $0.17 \pm 0.02^{\mathrm{ab}}$ & $0.18 \pm 0.03^{\mathrm{ab}}$ & $0.19 \pm 0.02^{\mathrm{a}}$ & $0.17 \pm 0.01^{\mathrm{ab}}$ \\
Lysozyme $^{5}$ & $3.16 \pm 0.17^{\mathrm{b}}$ & $3.61 \pm 0.12^{\mathrm{ab}}$ & $3.36 \pm 0.40^{\mathrm{ab}}$ & $3.80 \pm 0.30^{\mathrm{a}}$ & $3.35 \pm 0.11^{\mathrm{ab}}$ \\
SOD $^{6}$ & $76.3 \pm 8.7$ & $79.8 \pm 4.7$ & $77.8 \pm 5.4$ & $79.6 \pm 4.4$ & $81.8 \pm 4.3$ \\
GPX $^{7}$ & $58.2 \pm 9.9^{\mathrm{b}}$ & $69.6 \pm 7.5^{\mathrm{ab}}$ & $75.1 \pm 4.3^{\mathrm{a}}$ & $75.8 \pm 5.9^{\mathrm{a}}$ & $72.1 \pm 7.8^{\mathrm{ab}}$ \\
\hline
\end{tabular}

Values are mean of triplicate groups presented as mean \pm S.D. Values with different superscripts in the same row are significantly different $(P<0.05)$. The lack of superscript letter indicates no significant differences among treatments.

${ }^{1}$ Total hemocyte count $\left(10^{5} \mathrm{cells} / \mathrm{ml}\right) ;{ }^{2}$ Total protein $(\mathrm{mg} / \mathrm{ml}) ;{ }^{3}$ Nitro blue tetrazolium activity (absorbance)

${ }^{4}$ Phenoloxidase activity (absorbance); ${ }^{5}$ Lysozyme activity (Units $\left./ \mathrm{ml}\right) ;{ }^{6}$ Superoxide dismutase (\% inhibition)

${ }^{7}$ Glutathione peroxidase activity $(\mathrm{nmol} / \mathrm{min} / \mathrm{ml})$

$\mathrm{PO}$ and lysozyme activities of shrimp fed $0.2 \%$ diet were significantly higher than those fed the control diet. Even though numerically higher values of NBT and SOD activities and total protein levels were found in shrimp fed the AAMC supplemented diets, the differences were not significant. During the challenge test, the control diet group showed the lowest cumulative survival indicating the lowest disease resistance against $V$. harveyi (Fig. 1). Shrimp fed the $0.2 \%$ diet had a significantly higher survival rate than those fed the control diet. No significant difference was found among the shrimp groups fed the AAMC containing diets. 


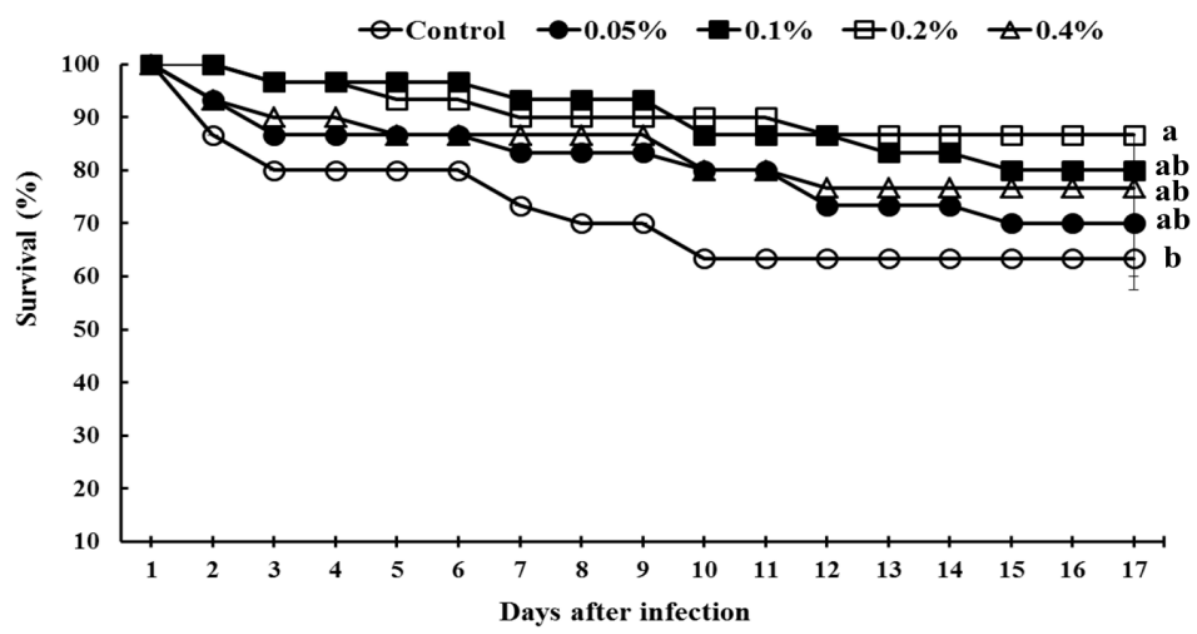

Fig. 1. Survival rate of $L$. vannamei after a challenge against $V$. harveyi. The shrimp were injected intramuscularly with $V$. harveyi suspension containing $1 \times 10^{6} \mathrm{CFU} / \mathrm{mL}$. The shrimp were not fed during the challenge period. The five diets were added with graded levels AAMC (anionic alkali mineral complex) by $0,0.05,0.1,0.2$ and $0.4 \%$ were fed to the shrimp for 6 weeks before the challenge test.

\section{Discussion}

Dietary supplementation of AAMC improved growth performance and feed utilization of $L$. vannamei in the present study. The growth-promoting impact of dietary administration of immunostimulants has been demonstrated in previous studies on fish species (Sakai, 1999; Guo et al., 2012; Cha et al., 2013) and shrimp (Bai et al., 2010). The beneficial effects of AAMC, on growth performance and feed utilization efficiency of olive flounder (Paralichthys olivaceus) were also found in our previous studies (Shin et al., 2014a; Shin et al., 2014b). However, it is still unclear how AAMC improves growth performance of the fish. One hypothesis is that sodium silicate, the main mineral ingredient in AAMC, is responsible for the growth promoting effect as it is decomposed quantitatively into bioavailable ortho-silicic acid in the acidic gastric juice that is absorbed in the body (Jurkic et al., 2013). The essential nature of silicon for growth and skeletal development was also observed in chicks and rats (Carlisle, 1970; Schwarz and Miline, 1972). Moreover, AAMC might have provided a good source of minerals involved in maintenance of skeletal formation and colloidal system, acid-base equilibrium and proper function of biologically important compounds like hormones and enzymes (Watanabe et al., 1997). Our recent studies have demonstrated that AAMC supplementation at concentrations from $0.1 \%$ to $0.2 \%$ in diets improved apparent nutrient digestibility and gastrointestinal morphology explaining increased growth and feed efficiency observed in fish fed AAMC (Shin et al., 2014b). It is therefore, reasonable to assume that those observations in the fish may partly account for improved growth and feed utilization efficiency of shrimp fed AAMC supplemented diets in the present study.

The immunostimulatory effect of AAMC has been shown in terrestrial animals (Yoo et al., 2001; Koo et al., 2006) and fish (Shin et al., 2014a, Shin et al., 2014b). The current results, in agreement with previous reports, strongly suggest that dietary supplementation of AAMC could positively affect the innate immune response of $L$. vannamei. The immunostimulatory effect of AAMC has been attributed to its mineral components and its ability to affect the membrane-associated lymphoid tissues (Koo et al., 2006). Although the exact mechanism has not yet been elucidated, dietary AAMC supplementation improved proliferation and activation of porcine immune cells in peripheral blood and the secondary lymphoid organs in pigs (Yoo et al., 2001). It was also suggested that the silica in AAMC solution might be responsible for improved immunity (Jurkic et al., 2013). Sub-chronic and short-term exposure of mice and rats to silica stimulated the immune system through the increase of neutrophils, natural killers (NK) cells, and T lymphocytes (Antonini et al., 2000). 
The improvement of immunity, either cellular or humoral, accompanied with enhanced disease resistance has already been demonstrated in other aquatic species (Kotzamanis et al., 2007; Yeh et al., 2009; Zokaeifar et al., 2012). Numerous immunostimulants have been reported to possess health benefits; stimulation of some immune parameters was reported (Sakai 1999). Dietary utilization of twig hot-water extract from Cinnamomum kanehirae has been reported to enhance nonspecific immune response of $L$. vannamei and disease resistance against $V$. harveyi. Similarly, dietary administration of Bacillus subtilis has shown to boost the immune response of $L$. vannamei (Zokaeifar et al., 2012) and Penaeus monodon (Pattukumar et al., 2013) and has up-regulated immune-related genes in the shrimp fed the $B$. subtilis. Therefore, the improved disease resistance of shrimp by the dietary AAMC supplementation in the present study is likely to be related to the significant enhancement of innate immunity including PO, lysozyme, GPx activities, and THC level. Furthermore, our results show that shrimp fed $0.4 \%$ AAMC diet did not have higher resistance to $V$. harveyi than the control group. Similarly, twig hot-water extract from $C$. kanekirae at the level of $2 \mu \mathrm{g} / \mathrm{g}$ shrimp1 significantly enhanced the disease resistance of white shrimp against $V$. alginolvticus while higher doses had no significant effect (Yeh et al. 2009). Our results suggest that excessive administration of a substance with potential immunostimulatory properties may not lead to higher levels of protection. Also, overdose and long-term administration of immunostimulants may not only reduce their efficiency (Harikrishnan et al., 2011) but induce immunosuppression (Sakai, 1999). This agrees with our previous results with flounder fed AAMC higher than $0.3 \%$ in diets (Shin et al., 2014a).

In conclusion, this study indicates that dietary supplementation of AAMC solution positively affects growth performance, feed utilization, innate immunity, and disease resistance of $L$. vannamei and its optimum dose could be approximately $2 \mathrm{~g} \mathrm{AAMC} / \mathrm{kg}$ diet. However, further investigations on this product are needed to examine the longterm effects at different growth stages of the shrimp.

\section{Acknowledgments}

This study was financially supported by Cargill Agri Purina, Inc. and Barodon - S.F. Corp., South Korea. This study was funded by the Korea Ministry of Oceans and Fisheries, which provided federal funds to support the 'Development of functional feed additives for shrimp using useful organic matter in biofloc-based rearing water' and was also supported by the National Research Foundation of Korea (NRF) grant funded by the Korea government (Ministry of Science, ICT \& Future Planning) (NRF2015R1A2A2A01004366).

\section{References}

Antonini J.M., Roberts J.R., Yang H.M., Barger M.W., Ramsey D., Castranova V. and J.Y.C. Ma, 2000. Effect of silica inhalation on the pulmonary clearance of a bacterial pathogen in Fischer 344 rats. Lung, 178(6), 341-350.

AOAC, 1995. Official methods of analysis. 16th ed. Association of Official Analytical Chemists, Arlington, Virginia, USA.

Bai N., Zhang W., Mai K., Wang X., Xu W. and H. Ma, 2010. Effects of discontinuous administration of $\beta$-glucan and glycyrrhizin on the growth and immunity of white shrimp Litopenaeus vannamei. Aquaculture, 306(1), 218-224.

Carlisle, E. M, 1970. A relationship between silicon and calcium in bone formation. In: Federation Proceedings. 9650 ROCKVILLE PIKE, BETHESDA, MD 20814-3998: FASEB J., p. A565-\&.

Cha J.H., Rahimnejad S., Yang S.Y., Kim K.W. and K. J. Lee, 2013. Evaluations of Bacillus spp. as dietary additives on growth performance, innate immunity and disease resistance of olive flounder (Paralichthys olivaceus) against Streptococcus iniae and as water additives. Aquaculture, 402, 50-57.

Chen Y.Y., Chen J.C., Tayag C.M., Li H.F., Putra D.F., Kuo Y.H., Bai J.C. and Y.H. Chang, 2016. Spirulina elicits the activation of innate immunity and increases resistance against Vibrio alginolyticus in shrimp. Fish Shellfish Immunol., 55, 690-698.

Choi S.I., Choi H.S., Jeon K.S., Yoo B.W. and Y.H. Park, 2005. Composition of multipurpose high functional alkaline solution composition, preparation thereof, and for the use of nonspecific immunostimulators. U.S. patent $6,884,440$. 
Dantzler A.S., Burnett K.G. and L.E. Burnett, 2001. Effects of hypercapnic hypoxia and respiratory burst inhibition on the bactericidal activity of hemocytes from the penaeid shrimp Litopenaeus vannamei. Am. Zool., 41(6), 1422-1423.

Flegel T.W., Lightner D.V., Lo C.F. and L. Owens, 2008. Shrimp disease control: past, present and future. Diseases in Asian Aquaculture VI. Fish Health Section, Asian Fisheries Society. Manila, Philippines, 505 pp.

Guo J.J., Kuo C.M., Chuang Y.C., Hong J.W., Chou R.L. and T.I. Chen, 2012. The effects of garlic-supplemented diets on antibacterial activity against Streptococcus iniae and on growth in orange-spotted grouper, Epinephelus coioides. Aquaculture, 364, 3338.

Harikrishnan R., Balasundaram C. and M.S. Heo, 2011. Impact of plant products on innate and adaptive immune system of cultured finfish and shellfish. Aquaculture, $317(1), 1-15$.

Hernández-López J., Gollas-Galván T. and F. Vargas-Albores, 1996. Activation of the prophenoloxidase system of the brown shrimp (Penaeus californiensis Holmes). Comp. Biochem. Physiol., Part C: Pharmacol., Toxicol. Endocrinol., 113(1), 61-66.

Jurkić L. M., Cepanec I., Pavelić S. K. and K. Pavelić, 2013. Biological and therapeutic effects of ortho-silicic acid and some ortho-silicic acid-releasing compounds: new perspectives for therapy. Nutr. Metab., 10(1), 1.

Koo H.C., Ryu S.H., Ahn H.J., Jung W.K., Park Y.K., Kwon N.H., Kim S.H., Kim J.M., Yoo B.W., Choi S.I., Davis W.C. and Y.H. Park, 2006. Immunostimulatory effects of the anionic alkali mineral complex BARODON on equine lymphocytes. Clin. Vaccine Immunol., 13(11), 1255-1266.

Kotzamanis Y.P., Gisbert E., Gatesoupe F.J., Infante J.Z. and C. Cahu, 2007. Effects of different dietary levels of fish protein hydrolysates on growth, digestive enzymes, gut microbiota, and resistance to Vibrio anguillarum in European sea bass (Dicentrarchus labrax) larvae. Comp. Biochem. Physiol., Part A: Mol. Integr. Physiol., 147(1), 205-214.

Marshall B.M. and S.B. Levy, 2011. Food animals and antimicrobials: impacts on human health. Clin. Microbiol. Rev., 24(4), 718-733.

Ng W.K., Koh C.B., Teoh C.Y. and N. Romano, 2015. Farm-raised tiger shrimp, Penaeus monodon, fed commercial feeds with added organic acids showed enhanced nutrient utilization, immune response and resistance to Vibrio harveyi challenge. Aquaculture, 449, 69-77.

Paglia D.E. and W.N. Valentine, 1967. Studies on the quantitative and qualitative characterization of erythrocyte glutathione peroxidase. Transl. Res., 70(1), 158-169.

Park B.K., Park Y.H. and K.S. Seo, 2000. Relation between lymphocyte subpopulations of peripheral blood and immune responses of modified live hog cholera virus vaccine in pigs treated with an ionized alkali mineral complex. J. Vet. Sci., 1(1), 49-52.

Pattukumar V., Kanmani P., Satish kumar R., Yuvaraj N., Paari A. and V. Arul, 2013. Improved resistance to Vibrio parahaemolyticus in black tiger shrimp Penaeus monodon treated with Streptococcus phocae PI80 and Bacillus subtilis. Isr J Aquac, 65.2013.807.

Rebouças R.H., de Sousa O.V., Lima A.S., Vasconcelos F.R., de Carvalho P.B. and dos Fernandes R.H.S. Vieira, 2011. Antimicrobial resistance profile of Vibrio species isolated from marine shrimp farming environments (Litopenaeus vannamei) at Ceará, Brazil. Environ. Res., 111(1), 21-24.

Sakai M., 1999. Current research status of fish immunostimulants. Aquaculture, 172(1), 63-92.

Schwarz K. and D.B. Milne, 1972. Growth-promoting effects of silicon in rats. Nature, 239(537), 333-334.

Sheikh A., Siddique M.A.M, Romkey S.S. and W.L. Shelton, 2017. Antibacterial function of herbal extracts on growth, survival and immunoprotection in the black tigher shrimp Penaeus monoeon. Fish Shellfish Immunol., 65, 52-58. 
Shin C.H., Bui H.T.D., Rahimnejad S., Cha J.H., Yoo B.W., Lee B.K. and J.D. Kim, 2014a. Effects of Dietary Supplementation of Barodon on Growth Performance, Innate Immunity and Disease Resistance of Juvenile Olive Flounder, Paralichthys olivaceus, Against Streptococcus iniae. J. World Aquacult. Soc., 45(3), 258-268.

Shin C.H., Cha J.H., Rahimnejad S., Jeong J.B., Yoo B.W., Lee B.K. and K.J. Lee, 2014b. Effects of Dietary Supplementation of Barodon, an Anionic Alkali Mineral Complex, on Growth Performance, Feed Utilization, Innate Immunity, Goblet Cell and Digestibility in Olive Flounder (Paralichthys olivaceus). Asian-Australas. J. Anim. Sci., 27(3), 383.

Watanabe T., Kiron V. and S. Satoh, 1997. Trace minerals in fish nutrition. Aquaculture, 151(1), 185-207.

Williams S.L., Jensen R.V., Kuhn D.D. and A.M. Stevens, 2017. Analyzing the metabolic capabilities of a Vibrio parahaemolyticus strain that causes Early Mortality Syndrome in shrimp. Fish Shellfish Immunol., 476, 44-48.

Yeh R.Y., Shiu Y.L., Shei S.C., Cheng S.C., Huang S.Y., Lin J.C. and C.H. Liu, 2009. Evaluation of the antibacterial activity of leaf and twig extracts of stout camphor tree, Cinnamomum kanehirae, and the effects on immunity and disease resistance of white shrimp, Litopenaeus vannamei Fish Shellfish Immunol., 27(1), 26-32.

Yoo B.W., Choi S.I., Kim S.H., Yang S.J., Koo H.C., Seo S.H. and Y.H. Park, 2001. Immunostimulatory effects of anionic alkali mineral complex solution Barodon in porcine lymphocytes. J. Vet. Sci., 2(1), 15-24.

Zokaeifar H., Balcázar J.L., Saad C.R., Kamarudin M.S., Sijam K., Arshad A. and N. Nejat, 2012. Effects of Bacillus subtilis on the growth performance, digestive enzymes, immune gene expression and disease resistance of white shrimp, Litopenaeus vannamei. Fish Shellfish Immunol., 33(4), 683-689. 